\title{
CARACTERIZAÇÃo QUÍMICA DO “PITCH” EM INDÚSTRIA DE CELULOSE E PAPEL DE Eucalyptus
}

\author{
Mariluze P. Cruz, Luiz C. A. Barbosa* e Célia R. A. Maltha \\ Departamento de Química, Universidade Federal de Viçosa, 36571-000 Viçosa - MG, Brasil \\ José L. Gomide \\ Departamento de Engenharia Florestal, Universidade Federal de Viçosa, 36571-000 Viçosa - MG, Brasil \\ Augusto F. Milanez \\ Companhia Suzano de Papel e Celulose, 08613-900 Suzano - SP, Brasil
}

Recebido em 23/2/05; aceito em 11/8/05; publicado na web em 8/2/06

\begin{abstract}
CHEMICAL CHARACTERIZATION OF PITCH IN Eucalyptus PULP AND PAPER INDUSTRY. The chemical analysis of the acetone, chloroform, toluene and methanol extracts of a pitch sample was carried out by IR and GC-MS, leading to the identification of sixty nine compounds, including fatty acids, alcohols and hydrocarbons. Analysis of the acetone extractive of a eucalyptus wood used in Brazil for pulp production was also carried out, resulting in identification of fifty nine compounds, including mainly fatty acids, phenolic compounds, $\beta$-sitosterol and other steroids. This analysis showed that pitch formation had a contribution from wood extractives and other sources of contamination. The results obtained and the methodology applied can be used by the pulp industry to develop new methods of pitch control.
\end{abstract}

Keywords: pitch; talc; wood extractive.

\section{INTRODUÇÃO}

A Associação Brasileira de Celulose e Papel - BRACELPA estima que 155 milhões de $t$ de polpa de madeira são produzidas por ano e prevê um aumento de $67 \%$ sobre esse valor até 2010 . A madeira usada no processo de fabricação dessa polpa é constituída de várias classes de compostos, como celulose, hemiceluloses e lignina, incluindo também os extrativos, que são formados por substâncias solúveis em água e em vários solventes orgânicos. Os componentes da madeira solúveis em água são sais inorgânicos, carboidratos, enquanto os compostos dos extrativos solúveis em solventes orgânicos pertencem à classe dos ácidos graxos, lipídios, terpenóides, compostos fenólicos ${ }^{1-3}$.

Vários compostos presentes nos extrativos, bem como alguns aditivos utilizados no processamento da polpa, podem formar depósitos denominados "pitch". O "pitch", que se deposita em várias partes do maquinário das fábricas, é responsável por redução da produção, aumento no custo de manutenção e operação dos equipamentos e aumento de defeitos no produto final, com conseqüente redução na qualidade do mesmo ${ }^{4,5}$. Com o aumento da escassez mundial de água, o maior rigor na legislação ambiental ${ }^{6}$ e as circunstâncias econômicas, as indústrias de celulose e papel têm sido obrigadas a reduzir o consumo de água ${ }^{7}$, e para isso têm implantado circuitos fechados, o que leva ao aparecimento de maior quantidade de "pitch".

Em função do sério problema que a formação de "pitch" causa para as indústrias de papel, essas têm envidado esforços para tentar encontrar uma solução definitiva. Entretanto, isso ainda não foi possível uma vez que o mecanismo de formação desses depósitos não é claramente entendido, pois sua composição química é complexa e variável. Assim, uma etapa fundamental em todo esse processo consiste em determinar a origem da contaminação, que depende do conhecimento da composição química do "pitch" 8,9 .

*e-mail: lcab@ufv.br
Vários trabalhos sobre a remoção de "pitch" envolvendo uso de enzimas, fungos e degradação bacteriana têm sido publicados, porém o custo e a dificuldade de operacionalização têm sido os entraves para sua implantação permanente $e^{7,10-15}$.

Embora a indústria de celulose e papel do Brasil ocupe a $7^{\text {a }}$ posição mundial entre as empresas do ramo, nenhum trabalho nacional científico sobre o "pitch" foi publicado até o momento. Dessa forma, o presente trabalho relata o primeiro estudo detalhado realizado no Brasil sobre a composição química de uma amostra de "pitch" e sua correlação com a composição dos extrativos da madeira utilizada no processo de produção da polpa. Os resultados obtidos podem vir a ser utilizados para planejamento de estratégias industriais no controle da formação de "pitch" .

\section{PARTE EXPERIMENTAL}

\section{Amostra de "pitch"}

O "pitch" analisado foi obtido em produção contínua de celulose com a composição da madeira $E$. grandis e E. saligna na relação de 77 e $23 \%$, respectivamente. A amostra de "pitch" (2,011 g) foi coletada em depósitos industriais, aderidos na raspa da prensa de desaguamento de polpa branqueada, enviada ao laboratório, secada à temperatura de $70-80{ }^{\circ} \mathrm{C}$ por $10 \mathrm{~h}$ e submetida à extração seqüencial em aparelho tipo Soxhlet, com acetona (24 h), clorofórmio (16 h), tolueno $(16 \mathrm{~h})$ e metanol $(72 \mathrm{~h})$. Os extratos obtidos foram concentrados em evaporador rotatório até a secura, resultando nos extratos codificados como EuP1 (acetona), EuP2 (clorofórmio), EuP3 (tolueno) e EuP4 (metanol). Após a extração seqüencial, o resíduo do "pitch" (EuR4) foi acidificado com solução de ácido clorídrico 1 mol L ${ }^{-1}$ até $\mathrm{pH} 2$, filtrado, secado e submetido à extração com acetona em aparelho Soxhlet, por $16 \mathrm{~h}$. O solvente foi removido em evaporador rotatório até a secura, sendo obtido o extrato EuP5 .

Três amostras de "pitch" (0,2 g cada) foram calcinadas em mufla a $500{ }^{\circ} \mathrm{C}$, por $2 \mathrm{~h}$, e foram determinadas as massas dos resíduos inorgânicos obtidos. 


\section{Amostra de madeira}

A amostra de cavacos de madeira usada era composta de $77 \%$ de Eucalyptus grandis, com 8,5 anos, e 23\% de Eucalyptus saligna, com 6,5 anos. As toras de madeira, antes de serem transformadas em cavacos, no pátio de madeira da fábrica, haviam sido estocadas no campo por um período de 5 meses após o corte. Uma amostra de cavacos industriais, de dimensões $3 \times 2 \times 0,2 \mathrm{~cm}$, coletada no pátio de cavacos da fábrica, foi secada em temperatura ambiente, moída e peneirada para obtenção de um pó com granulometria de 40-60 mesh. A serragem foi, então, extraída com acetona em aparelho tipo Soxhlet, por $6 \mathrm{~h}$. O solvente foi removido em evaporador rotatório até a secura, resultando na obtenção de um resíduo marrom avermelhado.

\section{Hidrólise do extrato da madeira}

Uma amostra do resíduo de extração com acetona $(20 \mathrm{mg})$ foi dissolvida em $10 \mathrm{~mL}$ de solução aquosa de $\mathrm{KOH}\left(1 \mathrm{~mol} \mathrm{~L} \mathrm{~L}^{-1}, 10 \%\right.$ $\mathrm{v} / \mathrm{v}$ de metanol). A mistura foi aquecida a $100{ }^{\circ} \mathrm{C}$, durante $1 \mathrm{~h}$, sob atmosfera de nitrogênio, resfriada e acidificada com solução aquosa de $\mathrm{HCl}\left(1 \mathrm{~mol} \mathrm{~L}^{-1}\right)$ até $\mathrm{pH} 2$ e, então, extraída com diclorometano $(3 \times 20 \mathrm{~mL})^{16-18}$. O solvente foi removido em evaporador rotatório até a secura.

\section{Análise por infravermelho (IV) e cromatografia gasosa acoplada à espectrometria de massas (CG-EM)}

A amostra dos extrativos da madeira e os extratos de "pitch", bem como os respectivos resíduos obtidos após cada extração, foram submetidos à análise por espectroscopia no infravermelho em espectrômetro Perkin Elmer Spectrum 1000, na região de 4000 a $500 \mathrm{~cm}^{-1}$. Os espectros foram registrados em pastilhas de $\mathrm{KBr}$.

Os extratos de "pitch" e de madeira obtidos antes e após a hidrólise alcalina foram sililados conforme metodologia descrita na literatura ${ }^{19}$. Esses extratos foram analisados por cromatografia gasosa acoplada à espectrometria de massas, utilizando-se o aparelho da marca Shimadzu, modelo GC-MS PQ5050A, com coluna capilar de sílica fundida DB-1 (30 m; 0,25 mm de diâmetro interno; filme de $0,25 \mu \mathrm{m}$ ) e hélio como gás de arraste. A temperatura do injetor foi de $290{ }^{\circ} \mathrm{C}$. Para a coluna a temperatura inicial foi de $80^{\circ} \mathrm{C}$ por $5 \mathrm{~min}$, aumentando de 80 a $285^{\circ} \mathrm{C}$ na taxa de $4{ }^{\circ} \mathrm{C} / \mathrm{min}$, permanecendo nesta temperatura por $40 \mathrm{~min}$. A temperatura do detector foi de $290{ }^{\circ} \mathrm{C}$ e na interface do sistema CG-EM foi de $290{ }^{\circ} \mathrm{C}^{16-18}$. O detector de massas operou com ionização por impacto de elétrons $(70 \mathrm{eV})$ e varredura de massas entre o intervalo de 30 a 600. A identificação dos compostos foi realizada através da comparação dos espectros de massas das amostras com aqueles existentes no banco de dados do aparelho (Wiley, $7^{\mathrm{a}}$ edição), com os dados da literatura ${ }^{20,21}$ e também com a injeção de amostras padrões.

Para análise quantitativa o aparelho CG-EM foi calibrado com compostos de referência, representativos das principais classes de compostos presentes nas amostras (utilizou-se hexadecan-1-ol, ácido hexadecanóico, glicose, ácido trans-ferúlico e $\beta$-sitosterol). A calibração foi feita usando-se os padrões internos ácido hexanodióico e o tetracosano (na concentração de $0,15625 \mathrm{mg} / \mathrm{mL}$ ), conforme descrito na literatura ${ }^{11}$. Os respectivos Fatores de Respostas Relativos (RRF) ${ }^{16,17,22}$ para os compostos de referência, necessários para quantificação das áreas dos picos de cada componente das amostras, foram calculados a partir da média de 16 análises, com os compostos na concentração de $0,15625 \mathrm{mg} / \mathrm{mL}$ após a sililação com BSTFA e TMSCl em piridina $^{20}$.

\section{RESULTADOS E DISCUSSÃO}

\section{Amostra de "pitch"}

A amostra de "pitch" analisada foi coletada durante um período em que se observou um aumento significativo na formação desse tipo de incrustação na fábrica. Essa amostra apresentou-se como um sólido marrom escuro. Visando determinar a origem de um número máximo possível dos constituintes orgânicos presentes nessa amostra, foi também coletada uma amostra da madeira utilizada no processo de polpação, no mesmo período em que se formou o depósito de "pitch" analisado.

Uma análise preliminar da amostra de "pitch" pela espectroscopia no infravermelho (Figura 1a) revelou uma banda de absorção larga em $3452 \mathrm{~cm}^{-1}$, correspondente ao estiramento da ligação OH, e absorções em 2954, 2921 e $2850 \mathrm{~cm}^{-1}$, correspondentes aos estiramentos de ligação $\mathrm{C}-\mathrm{H}$, indicando a presença de material de natureza alifática. As absorções em 3676, 1018 e $670 \mathrm{~cm}^{-1}$, correspondentes aos estiramentos de ligações O-H, Si-O e Si-O-Si, respectivamente ${ }^{23,24}$, indicaram a presença de talco na amostra. $\mathrm{O}$ talco é geralmente utilizado no processo de produção de polpa celulósica com objetivo de diminuir a pegajosidade do "pitch" e, assim, reduzir os problemas causados pelo mesmo ${ }^{25-27}$.

Nesse caso, observou-se que a eficiência de redução da pegajosidade não foi suficiente para eliminar a formação de depósitos. Industrialmente, convive-se com esta eficiência parcial, podendo ser melhorada à medida que se conhece mais o "pitch" e suas características químicas e físico-químicas. No caso em questão, foi constatado haver dosagem de talco insuficiente para reduzir a formação dos depósitos.

Considerando que a análise por infravermelho revelou que o "pitch" era formado, em parte, por material inorgânico, a amostra foi, em seguida, submetida à extração seqüencial com acetona, clorofórmio, tolueno e metanol. As massas dos extratos e resíduos obtidos após cada extração estão apresentadas na Tabela 1. O resíduo obtido após a extração com metanol (EuR4) foi acidificado, visando a conversão de possíveis sais de ácidos graxos em seus respectivos ácidos graxos. Esse resíduo foi submetido à extração com acetona, resultando no extrato EuP5, e no respectivo resíduo EuR5.

Pelos dados da Tabela 1 verifica-se que o total de material extraído corresponde a $31,3 \%$ da amostra e que a primeira extração com acetona resultou em apenas 15,9\% de extrativos. Esses dados demonstraram que o uso de apenas um solvente para estudo da composição química de "pitch", conforme encontrado na literatu$\mathrm{ra}^{18,28,29}$, não é adequado uma vez que o mesmo pode apresentar em sua composição compostos de polaridades muito diferentes e que podem estar fortemente adsorvidos em material inorgânico.

Para avaliar a eficiência do processo de extração seqüencial, o "pitch" foi calcinado a $500{ }^{\circ} \mathrm{C}$, o que resultou na obtenção de um resíduo inorgânico correspondente a $69,1 \%$ da amostra. Esse resultado está próximo do valor encontrado para o resíduo obtido

Tabela 1. Massas dos extratos e resíduos obtidos após extração seqüencial da amostra de "pitch"

\begin{tabular}{lccc}
\hline Solvente & Extrato & Massa / g;\% & Resíduo \\
\hline Acetona & EuP1 & 0,$32 ; 15,9$ & EuR1 \\
Clorofórmio & EuP2 & 0,$15 ; 7,4$ & EuR2 \\
Tolueno & EuP3 & 0,$07 ; 3,5$ & EuR3 \\
Metanol & EuP4 & 0,$07 ; 3,5$ & EuR4 \\
Acetona, após acidificação & EuP5 & 0,$02 ; 1,0$ & EuR5 \\
Total & $31,3 \%$ & & $68,7 \%$ \\
\hline
\end{tabular}



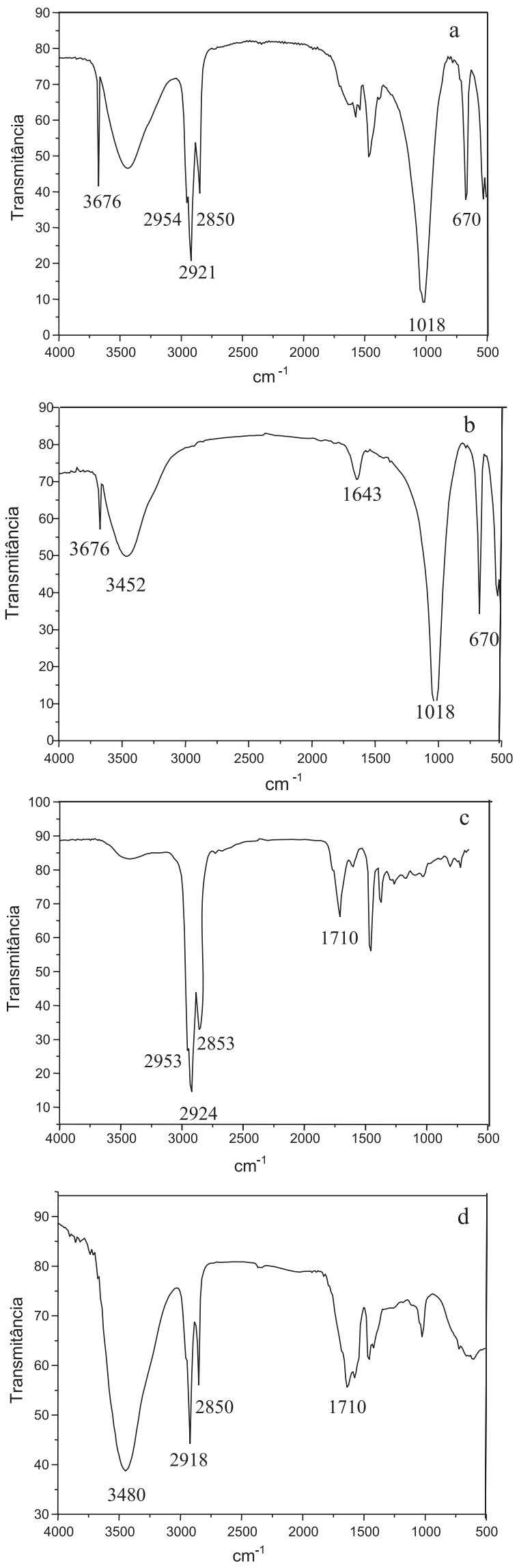

Figura 1. Espectros no infravermelho da amostra de "pitch": (a) antes da extração, (b) após a extração seqüencial (EuR5), (c) extrato em acetona (EuP1), (d) extrato em clorofórmio (EuP2) após as extrações $(68,7 \%)$, confirmando que o procedimento utilizado foi eficiente na extração dos compostos orgânicos.

O espectro no infravermelho do resíduo do "pitch" obtido após a extração seqüencial (EuR5 - Figura 1b) mostrou absorções típicas de talco e ausência das bandas características de compostos orgânicos alifáticos $\left(2954,2921\right.$ e $\left.2850 \mathrm{~cm}^{-1}\right)$, confirmando também que a extração seqüencial foi eficiente na remoção de material orgânico da amostra de "pitch". Nesse espectro foram observadas, ainda, bandas em 3452 e $1643 \mathrm{~cm}^{-1}$, relativas à presença de água adsorvida na amostra.

O espectro no infravermelho do extrato de "pitch" em acetona (EuP1, Figura 1c) apresentou bandas muito intensas com absorções em 2953, 2924 e 2853 cm$^{-1}$ (estiramento de ligação C-H) e uma banda de menor intensidade em $1710 \mathrm{~cm}^{-1}$ (estiramento de ligação $\mathrm{C}=\mathrm{O}$ ). Essas absorções sugerem a presença de compostos alifáticos, principalmente hidrocarbonetos e ácidos graxos. Os outros extratos obtidos do "pitch" (clorofórmio, tolueno e metanol) apresentaram espectros bastante semelhantes. Como ilustração, é apresentado, na Figura 1d, o espectro no infravermelho do extrato do "pitch" em clorofórmio, onde se observa uma banda larga e forte com máximo de absorção em $3480 \mathrm{~cm}^{-1}$ (estiramento de ligação O-H) e outras absorções fortes em 2918 e $2850 \mathrm{~cm}^{-1}$ (estiramento de ligação C-H). Essas absorções sugerem a presença de álcoois e compostos alifáticos, além de ácidos graxos, cuja banda característica ocorre em $1710 \mathrm{~cm}^{-1}$.

Com os resultados das análises no infravermelho tornou-se mais uma vez evidente que a acetona unicamente não foi suficiente para extração do "pitch". Apesar da utilização de acetona ser bastante relatada na literatura ${ }^{30}$, nota-se que ela não foi eficiente para a extração de compostos polares, o que tornou a extração seqüencial de fundamental importância para a caracterização química do "pitch".

Tendo em vista a caracterização parcial dos extratos pela espectroscopia no infravermelho, os mesmos foram sililados e analisados pela técnica CG-EM. A análise dos cromatogramas obtidos para os extratos de "pitch" (Figura 2) revelou a presença de um grande número de compostos. A análise dos espectros de massas permitiu identificar 69 compostos, conforme listado na Tabela 2. No extrato em acetona foi possível identificar 30 substâncias, o que equivale a $64,3 \%$ dos compostos presentes na amostra. No extrato em clorofórmio foram identificados 31 compostos, que totalizaram $95,8 \%$ da composição deste extrato. No extrato em tolueno foram identificados 36 compostos, o que equivale a $97,8 \%$ desse extrato e no extrato em metanol foram identificados 26 compostos, correspondendo a $67,1 \%$ do total. No extrato em acetona obtido após a acidificação (Eup5) foram identificados 43 compostos, totalizando $70,1 \%$ do extrato.

Além dos compostos listados na Tabela 2, vários outros compostos foram parcialmente caracterizados de acordo com os padrões de fragmentação das moléculas. Essa caracterização parcial permitiu classificá-los de acordo com o grupo químico, podendo os mesmos pertencerem à classe dos hidrocarbonetos (HC), ácidos graxos (AG), álcoois de cadeia longa (AL), carboidratos (CI) e compostos aromáticos (AR).

Os teores, expressos em mg/kg de "pitch", dessas classes de compostos que foram identificados completa ou parcialmente, são apresentados na Figura 3. Observa-se no extrato em acetona (EuP1) a predominância de hidrocarbonetos $(51,8 \%)$ e ácidos graxos (39,5\%). No extrato em clorofórmio (EuP2), os ácidos graxos representaram $86,3 \%$ da amostra e os álcoois de cadeia longa $12,4 \%$. Nos extratos em tolueno (EuP3), metanol (EuP4) e acetona obtido após acidificação (EuP5) também predominaram os ácidos graxos com 94,2, 77,7 e 62,8\%, respectivamente. Já os álcoois de cadeia longa foram observados em menor quantidade nesses mesmos ex- 
Tabela 2. Constituintes químicos do "pitch" (mg de composto/kg) identificados nos extratos em acetona (EuP1), clorofórmio (EuP2), tolueno (EuP3) e metanol (EuP4)

\begin{tabular}{|c|c|c|c|c|c|c|c|c|}
\hline Pico* & $\mathrm{TR} * *$ & Compostos & EuP1 & EuP2 & EuP3 & EuP4 & EuP5 & Total \\
\hline 1 & 7,704 & Octan-1-ol & 127,5 & 3736,5 & 23,9 & - & 13,8 & 3901,8 \\
\hline 2 & 8,406 & 1,2,4,5-tetrametilbenzeno & - & - & - & - & 1,7 & 1,7 \\
\hline 3 & 8,697 & Álcool benzílico & - & - & 7,9 & - & - & 7,9 \\
\hline 4 & 9,150 & Ácido diidroxiacético & 58,7 & 39,8 & 7,3 & 7,7 & - & 113,4 \\
\hline 5 & 10,400 & Ácido pent-2-enóico & - & - & - & - & 1,2 & 1,2 \\
\hline 6 & 10,850 & 2-metipropano-1,2-diol & - & - & - & - & 3,7 & 3,7 \\
\hline 7 & 11,733 & Ácido benzóico & - & - & 7,6 & 15,0 & - & 22,6 \\
\hline 8 & 12,399 & Dietilenoglicol & - & - & - & - & 6,4 & 6,4 \\
\hline 9 & 13,606 & Ácido fosfórico & - & 220,8 & - & - & - & 220,8 \\
\hline 10 & 14,242 & Glicerol & 68,4 & 34,5 & 3,1 & 60,3 & 78,8 & 245,1 \\
\hline 11 & 14,594 & Ácido butanodióico & - & - & - & - & 0,8 & 0,8 \\
\hline 12 & 15,392 & Ácido 2-metilbenzóico & - & - & - & 6,4 & - & 6,4 \\
\hline 13 & 15,865 & Ácido hidroxibutanodióico & - & - & - & - & 2,9 & 2,9 \\
\hline 14 & 16,084 & Ácido 3-fenoxipropanóico & - & 54,4 & - & - & - & 54,4 \\
\hline 15 & 16,292 & Ácido nonanóico & - & - & 2,5 & - & - & 2,5 \\
\hline 16 & 17,083 & Ácido metilfosfórico & 35,5 & - & 7,0 & - & - & 42,5 \\
\hline 17 & 19,583 & Ácido decanóico & - & 29,2 & 3,9 & - & - & 33,1 \\
\hline 19 & 24,122 & Hexadecano & 104,3 & - & - & - & - & 104,3 \\
\hline 20 & 25,567 & Ácido dodecanóico & - & 32,8 & 4,9 & - & - & 37,7 \\
\hline 22 & 26,182 & Ácido 1,2-benzenodicarboxilico & - & - & - & - & 2,5 & 2,5 \\
\hline 23 & 27,035 & Heptadecano & 335,4 & - & - & - & - & 335,4 \\
\hline 25 & 28,300 & Ácido tridecanóico & - & - & 3,35 & - & - & 3,3 \\
\hline 29 & 29,542 & Ácido nonanodióico & - & 82,5 & - & 113,2 & 2,0 & 197,7 \\
\hline 30 & 29,801 & Octadecano & 495,7 & - & - & - & - & 495,7 \\
\hline 32 & 30,994 & Ácido tetradecanóico & - & 99,1 & 32,1 & 19,5 & 3,1 & 153,9 \\
\hline 34 & 32,433 & Nonadecano & 719,5 & - & - & - & - & 719,5 \\
\hline 37 & 33,510 & Ácido pentadecanóico & 330,8 & 621,4 & 107,8 & 40,9 & 3,2 & 1104,0 \\
\hline 38 & 34,064 & Hexadecan-1-ol & - & - & 100,6 & 16,1 & 3,4 & 120,1 \\
\hline 40 & 34,946 & Icosano & 890,0 & - & - & - & - & 890,0 \\
\hline 41 & 35,176 & Ácido hexadec-9-enóico & - & - & 19,4 & 16,6 & 2,0 & 38,0 \\
\hline 42 & 35,967 & Ácido hexadecanóico & 2106,8 & 4661,3 & 900,0 & 343,7 & 29,2 & 8041,0 \\
\hline 44 & 37,337 & Henicosano & 885,8 & - & - & - & - & 885,8 \\
\hline 45 & 38,245 & Ácido heptadecanóico & 353,4 & 457,1 & 120,6 & 29,4 & 3,3 & 963,8 \\
\hline 46 & 38,762 & Octadecan-1-ol & - & - & 294,4 & 15,3 & 12,1 & 321,8 \\
\hline 47 & 39,627 & Docosano & 760,3 & - & - & - & - & 760,3 \\
\hline 48 & 39,788 & Ácido octadeca-9,12-dienóico & - & 167,6 & - & - & - & 167,6 \\
\hline 50 & 39,781 & Ácido octadec-9-enóico & 123,2 & 242,4 & 43,8 & 34,4 & 8,1 & 451,8 \\
\hline 52 & 39,999 & Ácido 2-hidroxiexadecanóico & - & - & - & 141,7 & 15,2 & 156,9 \\
\hline 53 & 40,482 & Ácido octadecanóico & 853,2 & 1020,9 & 322,4 & 92,9 & 19,5 & 2308,8 \\
\hline 54 & 41,819 & Tricosano & 710,7 & - & - & - & - & 710,7 \\
\hline 55 & 42,608 & Ácido nonadecanóico & 237,1 & 351,5 & 133,8 & 22,6 & 2,7 & 747,7 \\
\hline 56 & 42,930 & Icosan-1-ol & - & - & - & - & 2,0 & 2,0 \\
\hline 57 & 43,968 & Tetracosano & 781,6 & - & - & - & - & 781,6 \\
\hline 58 & 44,670 & Ácido icosanóico & 499,9 & 1146,0 & 486,1 & 66,5 & 16,9 & 2215,4 \\
\hline 59 & 45,943 & Pentacosano & 539,9 & - & - & - & - & 539,9 \\
\hline 60 & 46,650 & Ácido henicosanóico & 490,8 & 1367,7 & 661,2 & 68,3 & 14,0 & 2601,9 \\
\hline 61 & 47,025 & Docosanol & 83,6 & - & 25,7 & 22,9 & - & 132,2 \\
\hline 62 & 47,818 & Ácido 2-hidroxiicosanóico & - & - & - & - & 2,42 & 2,4 \\
\hline 63 & 47,888 & Hexacosano & 450,9 & - & - & - & - & 450,9 \\
\hline 64 & 48,556 & Ácido docosanóico & 703,1 & 2301,5 & 1161,0 & 90,5 & 36,7 & 4292,9 \\
\hline 65 & 49,642 & Ácido 2-hidroxienicosanóico & - & - & - & - & 5,2 & 5,2 \\
\hline 66 & 49,764 & Heptacosano & 339,3 & - & - & - & - & 339,3 \\
\hline 67 & 50,396 & Ácido tricosanóico & 512,5 & 2104,3 & 1109,2 & 61,3 & 46,0 & 3833,4 \\
\hline 69 & 51,557 & Ácido 2-hidroxidocosanóico & - & 125,9 & - & - & 18,5 & 144,4 \\
\hline 71 & 52,179 & Ácido tetracosanóico & 824,0 & 3710,2 & 1867,8 & 105,9 & 94,6 & 6602,5 \\
\hline 72 & 53,120 & Ácido 2-hidroxitricosanóico & - & 85,9 & - & - & 13,3 & 99,2 \\
\hline 73 & 53,889 & Ácido pentacosanóico & 209,3 & 1116,0 & 615,1 & 18,4 & 30,2 & 1989,0 \\
\hline 75 & 54,766 & Ácido 22-hidroxidocosanóico & - & 320,6 & 161,6 & 73,7 & 23,1 & 578,9 \\
\hline 76 & 54,924 & Ácido 2-hidroxitetracosanóico & - & 211,4 & - & - & 26,2 & 237,6 \\
\hline
\end{tabular}


Tabela 2. Continuação

\begin{tabular}{|c|c|c|c|c|c|c|c|c|}
\hline Pico* & $\mathrm{TR} * *$ & Compostos & EuP1 & EuP2 & EuP3 & EuP4 & EuP5 & Total \\
\hline 77 & 55,562 & Ácido hexacosanóico & 624,1 & 3016,4 & 1487,1 & 28,7 & 98,6 & 5255,0 \\
\hline 79 & 56,348 & Ácido 23-hidroxitricosanóico & - & - & 35,3 & - & 5,9 & 41,2 \\
\hline 80 & 56,381 & Ácido 2-hidroxipentacosanóico & - & - & - & - & 6,9 & 6,9 \\
\hline 81 & 57,279 & Ácido heptacosanóico & - & 150,4 & 86,1 & - & 4,8 & 241,4 \\
\hline 82 & 57,533 & Octacosan-1-ol & - & - & 18,4 & - & - & 18,4 \\
\hline 83 & 58,106 & Ácido 24-hidroxitetracosanóico & - & 911,5 & 509,5 & 80,0 & 124,7 & 1625,7 \\
\hline 84 & 58,146 & Ácido 2-hidroxiexacosanóico & - & - & - & - & 5,8 & 5,8 \\
\hline 85 & 59,235 & Ácido octacosanóico & - & 758,5 & 404,4 & - & 26,6 & 1189,5 \\
\hline 87 & 60,158 & Ácido 25-hidroxipentacosanóico & - & - & 46,7 & - & 169,8 & 216,4 \\
\hline 90 & 62,672 & Ácido 26-hidroxiexacosanóico & - & 381,3 & 287,9 & - & 11,9 & 681,1 \\
\hline \multicolumn{3}{|c|}{ Total identificado } & 15255,4 & 29559,4 & 11109,2 & 1591,9 & 999,5 & 58515,4 \\
\hline \multicolumn{3}{|c|}{ Total identificado parcialmente } & 3535,7 & 524,8 & 40,9 & 248,2 & 7,5 & 4357,1 \\
\hline \multicolumn{3}{|c|}{ Total não identificado } & 4887,1 & 773,8 & 215,3 & 533,4 & 405,7 & 6815,3 \\
\hline
\end{tabular}

*O número do pico refere-se aos cromatogramas na Figura 2.**Para os compostos que contêm hidroxila(s) o tempo de retenção corresponde ao do derivado sililado.

tratos $(4,1,5,4$ e $8,3 \%$, respectivamente). Carboidratos foram também identificados nos extratos em clorofórmio $(0,5 \%)$ e em metanol $(2,5 \%)$. Os compostos aromáticos ocorreram em quantidade muito pequena nos extratos em tolueno $(0,1 \%)$, metanol $(1,0 \%)$ e acetona após acidificação $(0,6 \%)$.

Novamente, evidencia-se pela Figura 3 que a extração apenas com acetona não é suficiente para se obter informação completa sobre a composição química do "pitch", uma vez que esse solvente extraiu principalmente hidrocarbonetos, os quais representam apenas $17 \%$ da amostra. A extração seqüencial mostrou que dentre os compostos orgânicos que formam o "pitch", 72,5\% correspondem a ácidos graxos.

\section{Amostra de madeira}

O extrato em acetona da madeira de Eucalyptus utilizada no processo de produção da polpa celulósica, na ocasião de coleta da amostra de "pitch", foi analisado antes e após a hidrólise alcalina. A hidrólise fez-se necessária uma vez que o espectro no infravermelho do extrato em acetona apresentou uma banda de absorção característica de ésteres $\left(1730 \mathrm{~cm}^{-1}\right)$. Apesar de bastante eficiente para identificar e quantificar um vasto número de extrativos, a análise cromatográfica com utilização de coluna capilar longa (30 m) não é adequada para análise de esteróides esterificados e triacilglicerídeos. Nesse sentido, a hidrólise alcalina seguida de acidificação teve como objetivo a formação do álcool e do ácido correspondentes dos ésteres ${ }^{31}$.

Observa-se nos cromatogramas dos extrativos da madeira um total de aproximadamente 100 picos (Figura 4). Nos extratos não hidrolisado e hidrolisado foram completamente identificados 42 compostos $(43,3 \%)$ e 57 compostos $(73,9 \%)$, respectivamente.

A análise dos cromatogramas, apresentados na Figura 4 e os dados da Tabela 3, revelaram um aumento significativo nos teores de ácidos graxos e de $\beta$-sitosterol (composto 88) após a hidrólise. Esse aumento é notadamente evidenciado na Figura 5, que apresenta o teor das principais classes de compostos presentes no extrato antes e após a hidrólise alcalina. Com a hidrólise, alguns novos compostos foram também detectados, mostrando que os mesmos existiam anteriormente esterificados na madeira.

Essas análises revelaram que os esteróides (ES) estão presentes em maior quantidade nos extrativos da madeira, correspondendo a 41,99\% dos compostos identificados antes da hidrólise e 51,76\% após a hidrólise. Dentre os esteróides identificados, o $\beta$-sitosterol foi o principal constituinte. A predominância desse composto era, de fato, esperada uma vez que se encontram descritos na literatura vários estudos com extrativos de Eucalyptus globulus relatando a ocorrência do $\beta$-sitosterol como principal constituinte dos mesmos ${ }^{16,31}$.

Os ácidos graxos (AG) também foram identificados em quantidade expressiva totalizando $15,22 \%$ do extrato, dos quais $3,83 \%$ são ácidos insaturados e 3,15\% hidroxiácidos identificados antes da hidrólise. Após a hidrólise observou-se um aumento para 37,20\% de ácidos graxos no extrato, sendo $10,6 \%$ correspondentes a ácidos graxos insaturados e 5,37\% a hidroxiácidos. Dentre os ácidos graxos hidroxilados nas posições $\alpha$ e $\omega$, estão os ácidos 2-hidroxidocosanóico, 2-hidroxitricosanóico, 2-hidroxitetracosanóico, 2hidroxipentacosanóico e 2-hidroxiexacosanóico, sendo o mais abundante o ácido 2-hidroxitetracosanóico. Considerando-se os compostos $\omega$-hidroxilados identificados, destacaram-se os ácidos 22hidroxidocosanóico (presente em maior quantidade), 23hidroxitricosanóico e 24-hidroxitetracosanóico, que são de ocorrência pouco comum em madeira. Tais compostos são freqüentemente encontrados em plantas herbáceas, algumas espécies de esponjas e bactérias. Entretanto, já foi descrita a ocorrência desses ácidos no extrato da madeira de E. globulus após a hidrólise alcalina ${ }^{17}$.

Os compostos aromáticos (AR) foram encontrados no extrato em acetona antes $(13,87 \%)$ e após a hidrólise $(5,20 \%)$. Dos compostos aromáticos identificados, o 3-(4-hidroxi-3-metoxifenil)prop-2enol (álcool coniferílico), ácido 4-hidroxi-3-metoxibenzóico (ácido vanílico) e 4-hidroxi-3,5-dimetoxibenzóico (ácido siríngico) já haviam sido identificados em $E$. globulus anteriormente ${ }^{17}$. Os demais compostos aromáticos, tais como o ácido 3,4-diidroxibenzóico e ácido 3,4,5-triidroxibenzóico (ácido gálico), foram identificados em madeira de E. globulus, após pirólise ${ }^{32,33}$. Os compostos aromáticos são formados a partir da lignina que, apesar de não ser considerada extrativo, pode ser pirolisada produzindo misturas de fenóis relativamente simples como esses identificados no extrato ${ }^{34}$.

Os álcoois de cadeia longa (AL) representaram 7,44\% do total de compostos identificados antes da hidrólise e 3,92\% após a hidrólise alcalina. Os hidrocarbonetos (HC) contribuíram com apenas $0,09 \%$ do teor total do extrato antes e $0,34 \%$ após a hidrólise alcalina.

Os carboidratos (CI), principalmente as hexoses, foram parcialmente identificados no extrato em acetona, eqüivalendo a $14,71 \%$. Com a análise do extrato em acetona antes e após a hidrólise foi possível identificar todos os componentes voláteis que se encontravam na forma livre e esterificada. Essa análise é de grande im- 

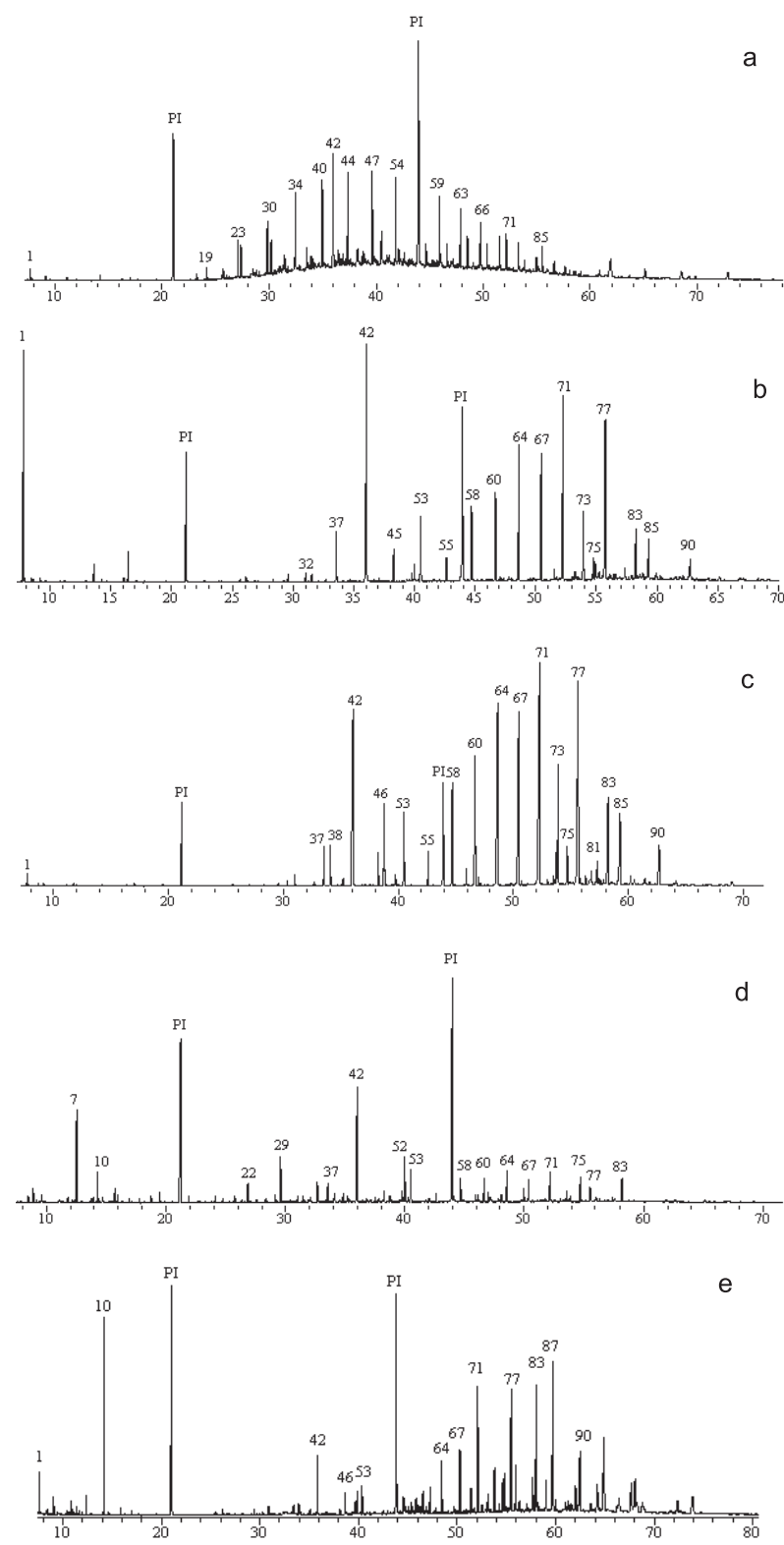

Figura 2. Cromatogramas de íons totais dos extratos do "pitch" formado durante o cozimento de madeira de Eucalyptus sp. Extratos em: (a) acetona, (b) clorofórmio, (c) tolueno, (d) metanol, (e) acetona, após acidificação. PI: Padrão Interno

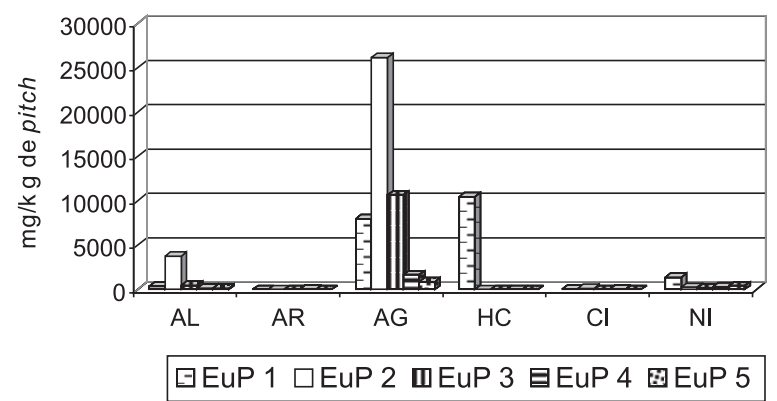

Figura 3. Constituintes químicos identificados no pitch formado durante o cozimento da madeira de Eucalyptus sp. Extratos em: acetona (EuP1), clorofórmio (EuP2), tolueno (EuP3), metanol (EuP4) e acetona após acidificação (EuP5). $A L=$ álcoois, $A R=$ aromáticos, $A G=$ ácidos graxos, $H C=$ hidrocarbonetos, $C I=$ carboidratos,$N I=$ não identificados
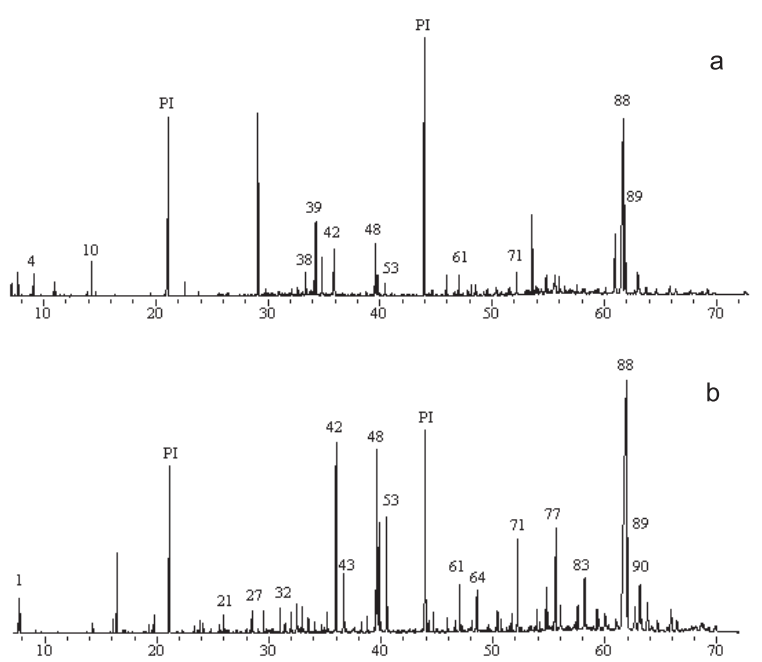

Figura 4. Cromatogramas de íons totais dos extratos da madeira de Eucalyptus sp antes (a) e após a hidrólise alcalina (b). PI: Padrão Interno

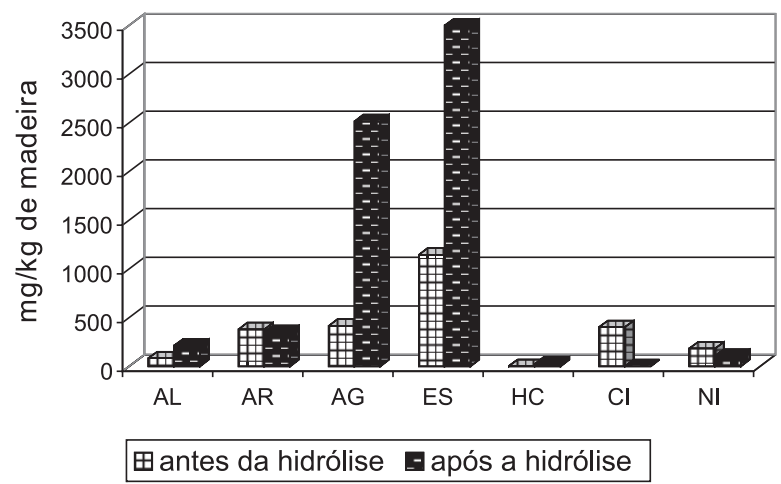

Figura 5. Constituintes químicos identificados no extrato em acetona da madeira de Eucalyptus sp antes e após a hidrólise alcalina. $A L=$ álcool, $A R$ = aromáticos, $A G=$ ácidos graxos, ES = esteróides, $H C=$ hidrocarbonetos, $C I=$ carboidratos, $N I=$ não identificados

portância para a obtenção de maiores informações a respeito da composição química dos extrativos da madeira de Eucalyptus sp, pois permite estabelecer uma melhor comparação com os compostos identificados na amostra de "pitch".

Conforme mencionado na parte experimental, a madeira utilizada foi estocada no campo por um período de 5 meses após o corte. O tempo prolongado de exposição da madeira às condições ambientais pode favorecer um processo de degradação biológica ${ }^{35-37}$, que pode, eventualmente, acarretar variações na composição qualitativa e quantitativa da mesma, em relação aos constituintes químicos da madeira recém-cortada.

\section{Comparação entre os compostos identificados no "pitch" e na madeira}

As Tabelas 2 e 3 mostram que alguns dos compostos identificados no "pitch" também foram identificados na madeira. Os ácidos graxos, incluindo-se os ácidos hidroxilados, estavam presentes em grande quantidade na madeira e também no "pitch". Uma vez que ácidos graxos não são comumente encontrados nos aditivos aplicados no processo desta indústria, a ocorrência dos mesmos no "pitch" e na madeira sugere que a madeira seja a principal fonte de origem de tais compostos e, portanto, contribuiria para a formação dos depósitos de "pitch". 
Tabela 3. Constituintes químicos da madeira (mg de composto/kg de madeira) de E. grandis e E. saligna (77:23) identificados no extrato em acetona obtido antes e após a hidrólise alcalina

\begin{tabular}{|c|c|c|c|c|}
\hline Pico* & $\mathrm{TR}^{* *}$ & Compostos & Antes da Hidrólise & Após a Hidrólise \\
\hline 1 & 7,716 & Octanol & 26,7 & 44,8 \\
\hline 4 & 9,183 & Ácido diidroacético & - & 2,9 \\
\hline 10 & 14,270 & Glicerol & 40,8 & 10,2 \\
\hline 14 & 16,075 & Ácido 3-fenoxipropanóico & - & 22,2 \\
\hline 17 & 19,563 & Ácido decanóico & - & 3,4 \\
\hline 18 & 23,334 & Benzofenona & - & 10,3 \\
\hline 20 & 25,563 & Ácido dodecanóico & - & 9,4 \\
\hline 21 & 25,974 & 4-hidroxi-3,5-dimetoxibenzaldeído & - & 26,8 \\
\hline 24 & 27,990 & (4-hidroxi-3,5-dimetoxifenil)acetaldeido & - & 4,6 \\
\hline 26 & 28,325 & Ácido 4-(hidroxifenil)propanóico & - & 3,6 \\
\hline 27 & 28,483 & Ácido 4-hidroxi-3-metoxibenzóico & - & 32,4 \\
\hline 28 & 29,018 & Ácido 4-(hidroxifenil)prop-2-enóico & - & 4,6 \\
\hline 30 & 29,800 & Octadecano & - & 2,9 \\
\hline 31 & 30,400 & Ácido 3,4-diidroxibenzóico & 2,9 & - \\
\hline 32 & 30,968 & Ácido tetradecanóico & 8,1 & 27,9 \\
\hline 33 & 31,940 & Ácido 4-hidroxi-3,5-dimetoxibenzóico & 7,0 & 29,7 \\
\hline 35 & 32,468 & Ácido (2Z)-3-(4-hidroxi-3-metoxifenil)prop-2-enóico & - & 49,5 \\
\hline 36 & 33,100 & 3-(4-hidroxi-3-metoxifenil)prop-2-enol & 5,5 & 6,0 \\
\hline 37 & 33,508 & Ácido pentadecanóico & 2,5 & 18,1 \\
\hline 38 & 34,066 & Hexadecan-1-ol & 16,6 & 10,2 \\
\hline 39 & 34,272 & Ácido 3,4,5-triidroxibenzóico & 147,7 & - \\
\hline 41 & 35,192 & Ácido hexadec-9-enóico & 3,6 & 25,0 \\
\hline 42 & 35,937 & Ácido hexadecanóico & 64,1 & 304,7 \\
\hline 43 & 36,700 & Ácido (2E)-3-(4-hidroxi-3-metoxifenil)prop-2-enóico & - & 87,3 \\
\hline 45 & 38,242 & Ácido heptadecanóico & 2,48 & 17,4 \\
\hline 46 & 38,732 & Octadecan-1-ol & 4,1 & 21,4 \\
\hline 47 & 39,392 & Docosano & - & 3,3 \\
\hline 48 & 39,575 & Ácido octadeca-9,12-dienóico & 68,9 & 452,8 \\
\hline 49 & 39,625 & Isômero do ácido octadeca-9,12-dienóico & 2,7 & 18,6 \\
\hline 50 & 39,771 & Ácido octadeca-9-enóico & 27,1 & 204,6 \\
\hline 51 & 39,942 & Isômero do ácido octadec-9-enóico & 2,2 & 17,8 \\
\hline 53 & 40,468 & Ácido octadecanóico & 14,0 & 213,2 \\
\hline 55 & 42,610 & Ácido nonadecanóico & - & 5,1 \\
\hline 58 & 44,660 & Ácido icosanóico & 7,2 & 35,7 \\
\hline 60 & 46,642 & Ácido henicosanóico & 4,4 & 28,5 \\
\hline 61 & 47,023 & Docosan-1-ol & 20,9 & 73,7 \\
\hline 64 & 48,555 & Ácido docosanóico & 11,7 & 70,0 \\
\hline 67 & 50,394 & Ácido tricosanóico & 9,7 & 38,4 \\
\hline 68 & 50,725 & Tetracosan-1-ol & 2,8 & 17,7 \\
\hline 69 & 51,529 & Ácido 2-hidroxidocosanóico & 10,9 & 15,5 \\
\hline 70 & 51,706 & Esqualeno & 2,4 & 11,1 \\
\hline 71 & 52,182 & Ácido tetracosanóico & 30,4 & 183,7 \\
\hline 72 & 53,237 & Ácido 2-hidroxitricosanóico & 5,6 & 6,1 \\
\hline 73 & 53,902 & Ácido pentacosanóico & 11,0 & 38,9 \\
\hline 74 & 54,183 & Hexacosan-1-ol & 2,0 & 12,9 \\
\hline 75 & 54,738 & Ácido 22-hidroxidocosanóico & 17,7 & 80,7 \\
\hline 76 & 54,898 & Ácido 2-hidroxitetracosanóico & 22,8 & 30,0 \\
\hline 77 & 55,575 & Ácido hexacosanóico & 23,4 & 220,3 \\
\hline 78 & 55,995 & Estigmasta-3,5-dieno & 27,3 & 64,8 \\
\hline 79 & 56,367 & Ácido 23-hidroxitricosanóico & - & 2,7 \\
\hline 80 & 56,498 & Ácido 2-hidroxipentacosanóico & 10,5 & 5,8 \\
\hline 82 & 57,547 & Octacosan-1-ol & 10,4 & 44,4 \\
\hline 83 & 58,122 & Ácido 24-hidroxitetracosanóico & 8,3 & 144,0 \\
\hline 84 & 58,271 & Ácido 2-hidroxiexacosanóico & 10,2 & 9,9 \\
\hline 85 & 59,218 & Ácido octacosanóico & 3,5 & 59,8 \\
\hline 86 & 59,450 & Campesterol & 9,5 & 37,1 \\
\hline 88 & 61,697 & $\beta$-sitosterol & 781,8 & 2404,1 \\
\hline
\end{tabular}


Tabela 3. Continuação

\begin{tabular}{lllcc}
\hline Pico* & TR** & Compostos & Antes da Hidrólise & Após a Hidrólise \\
\hline 89 & 61,886 & B-sitostanol & 102,5 & 301,1 \\
90 & 62,683 & Ácido 26-hidroxiexacosanóico & - & 68,3 \\
\hline \multicolumn{2}{l}{ Total identificado } & & 1594,0 & 5695,9 \\
\multicolumn{2}{l}{ Total identificado parcialmente } & 952,3 & 950,4 \\
\multicolumn{2}{l}{ Total não identificado } & & 1134,3 & 1062,7 \\
\hline
\end{tabular}

*O número do pico refere-se aos cromatogramas na Figura 4.** Para os compostos que contém hidroxila(s) o tempo de retenção corresponde ao do derivado sililado.

Pode-se observar ainda que os 12 hidrocarbonetos identificados na amostra de "pitch" (Tabela 2) não devem ter sido oriundos da madeira (Tabela 3), o que indica uma outra fonte de contaminação, provavelmente os aditivos usados durante o processo de produção de papel, já que a água branca da máquina de papel entra em contato com a polpa celulósica antes do ponto de coleta do "pitch".

Outra consideração relevante a ser feita em relação aos extrativos da madeira é que $41,99 \%$ do extrato da madeira em acetona e $51,76 \%$ do extrato obtido após a hidrólise alcalina correspondem a esteróides, principalmente o $\beta$-sitosterol ${ }^{38}$. Apesar da literatura relatar que o $\beta$-sitosterol é o principal componente em amostras de "pitch" provenientes de fábricas na Europa ${ }^{7,29,30}$, surpreendentemente esse esteróide não foi encontrado na amostra de "pitch" analisada. Disso pode-se formular a hipótese de que com a estocagem da madeira ocorreu a degradação do $\beta$-sitosterol.

\section{CONCLUSÕES}

Os estudos realizados demonstraram a necessidade de uma extração seqüencial com diferentes solventes para uma melhor caracterização química de amostras de "pitch". A análise cromatográfica dos extratos de "pitch" permitiu identificar principalmente ácidos graxos que, por terem sido identificados na madeira, podem ser oriundos dos extrativos da mesma. Os álcoois graxos encontrados em menor quantidade também foram identificados na madeira. Os hidrocarbonetos representam uma outra classe de compostos predominantes no "pitch", tendo sido identificados 12 hidrocarbonetos. Por não terem sido identificados nos extrativos da madeira, os hidrocarbonetos certamente são oriundos de outra fonte de contaminação na linha de produção da indústria. A metodologia empregada nesse trabalho pode vir a ser utilizada para estudos sistemáticos de amostras de "pitch" e assim permitir às indústrias o planejamento de estratégias para reduzir a formação desse tipo de resíduo indesejável, que causa tantos prejuízos às indústrias.

\section{AGRADECIMENTOS}

À Fundação de Amparo à Pesquisa do Estado de Minas Gerais (FAPEMIG) e ao Conselho Nacional de Desenvolvimento Científico e Tecnológico (CNPq) pelo apoio financeiro.

\section{REFERÊNCIAS}

1. Shatalov, A. A.; Evtuguin, D. V.; Pascoal-Neto, C.; Carbohydr. Res. 1999, $320,93$.

2. Verenich, S.; Molina, V. G.; Kallas, J.; Advances in Environmental Research 2002, 8, 293.

3. Yokoi, H.; Nakase, T.; Goto, K.; Ishida, Y.; Ohtani, H.; Tsuge, S.; Sonoda, T.; J. Anal. Appl. Pyrolysis 2003, 67, 191.
4. Dorado, J.; Claassen, F. W.; Vaan-Beek, T. A.; Lenon, G.; Wijnberg, J. B. P. A.; Sierra-Alvarez, R.; J. Biotechnol. 2000, 80, 231; Martínez-Íñigo, M. J.; Gutiérrez, A.; Río, J. C.; Martínez, M. J.; Martínez, A. T.; J. Biotechnol. 2000, 84, 119.

5. Randrup, R.; Resumos do XVII Congresso Anual da Associação Brasileira de Celulose e Papel, São Paulo, Brasil, 1984.

6. Barros, M. J.; Nozaki, J.; Quim. Nova 2002, 25, 736.

7. Gutiérrez, A.; Romero, J.; Río, J. C.; Chemosphere 2001, 44, 1237.

8. Hassler, T.; Tappi J. 1988, 71, 195.

9. Biermann, C. J.; Lee, M. K.; Tappi J. 1990, 73, 127.

10. Stranger-Johannessen, M.; Biotechnol. Adv. 1984, $2,319$.

11. Fischer, K.; Messner, K.; Enzyme Microb. Technol. 1992, 14, 470.

12. Fischer, K.; Messner, K.; Tappi J. 1992, 75, 130.

13. Jaeger, K. E.; Reetz, M. T.; Tibtech. 1998, 16, 396

14. Breen, A.; Curr. Opin. Biotechnol. 1999, 10, 252.

15. Yu, Z.; Mohn, W. W.; Water Res. 2002, 36, 2793.

16. Freire, C. S. R.; Silvestre, A. J. D.; Pascoal-Neto, C.; Cavaleiro, J. A. S.; Holzforschung 2002, 56, 372.

17. Freire, C. S. R.; Silvestre, A. J. D.; Pascoal-Neto, C.; Holzforschung 2002, $56,143$.

18. Silvestre, A. J. D.; Freire, C. S. R.; Pascoal-Neto, C.; Resumos do $7^{\text {th }}$ Brazilian Symposium on the Chemistry of Lignins and Other Wood Components, Belo Horizonte, Brasil, 2001.

19. Örsa, F.; Holmbom, B.; J. Pulp Pap. Sci. 1994, 12, 361.

20. Cruz, M. P.; Dissertação de Mestrado, Universidade Federal de Viçosa, Brasil, 2004.

21. Barros, C. S. R. F.; Tese de Doutorado, Universidade de Aveiro, Portugal, 2003.

22. Grant, D. W.; Capillary Gas Chromatography, John Wiley \& Sons: Chichester, 1996.

23. Nakanishi, K.; Solomon, P. H.; Infrared Absorption Spectroscopy, $2^{\text {nd }}$ ed., Holden-Day: San Francisco, 1977.

24. Smolander, K.; Saastamoinen, A.; Ahlgrén, M.; Anal. Chim. Acta 1989, $217,353$.

25. Dunlop-Jones, N.; Douek, M.; Allen, L. H.; J. Pulp Pap. Sci. 1987, 13, 18.

26. Allen, L. H.; Douek, M.; J. Pulp Pap. Sci. 1993, 19, 313.

27. Douek, M.; Allen, L. H.; J. Pulp Pap. Sci. 1991, 17, 171.

28. Zheng, H.; Uhing, M. C.; Cosper, D. R.; J. Pulp Pap. Sci. 2002, $28,204$.

29. Gutiérrez, A.; Río, J. C.; González-Vila, F, J.; Martín, F.; J. Chromatogr., A 1998, 823, 449.

30. Río, J. C.; Romero, J.; Gutiérrez, A.; J. Chromatogr., A 2000, 874, 235.

31. Charlet, P.; Lenon, G; Joseleau, B.; Chareyre, P.; Resumos do $9^{\text {th }}$ International Wood and Pulping Chemistry Symposium, Montreal, Canadá, 1997.

32. González-Vila, F. J.; Río, J. C.; Martín, F.; Verdejo, T.; J. Chromatogr., A 1996, 750, 155.

33. Río, J. C.; Hernando, M.; Landín, P.; Gutiérrez, A.; Romero, J.; J. Anal. Appl. Pyrolysis 2003, 68-69, 251.

34. Ralph, J.; Hatfield, R. D.; J. Agric. Food Chem. 1991, 39, 1426.

35. Dorado, J.; Beek, T. A.; Claassen, F. W., Alvarez-Sierra, R.; Wood Sci. Technol. 2001, 35, 117.

36. Dorado, J.; Claassen, F. W., Beek, T. A.; Lenon, G.; Alvarez-Sierra, R.; J. Biotechnol. 2000, 80, 231.

37. Burnes, T. A.; Blanchette, R. A.; Farrel, R. L.; Appl. Environ. Microbiol. 2000, 66, 5201.

38. Cruz, M. P.; Maltha, C. R. A.; Barbosa, L. C. A.; Gomide, J. L.; Milanez, A. F.; Resumos do XVII Encontro Regional da Sociedade Brasileira de Química, Juiz de Fora, Brasil, 2003. 